\title{
Boots on the Ground and Shots in Arms: A West Virginia Pharmcist on COVID-19 Vaccinations
}

\author{
Charles Massey, PharmD'
}

ABSTRACT

Author affiliations are listed at the end of this article.

Since the Emergency Use Authorizations were approved in December 2020, and the first two COVID-19 vaccinations began to arrive around the globe, the national and world spotlight quickly shone on what many would deem to be an unlikely candidate: the state of West Virginia.

Corresponding Author: Charles Massey, PharmD Fruth Pharmacy wvudoctor@aol.com
Since the Emergency Use Authorizations were approved in December 2020, and the first two COVID-19 vaccinations began to arrive around the globe, the national and world spotlight quickly shone on what many would deem to be an unlikely candidate: the state of West Virginia. Although the state is often portrayed as backward and impoverished, those who call West Virginia home were not surprised that this undiscovered "diamond in the rough," as Governor Jim Justice refers to it, worked together to propel the state early on to the top ranks for immunizations administered to the population.

Preparations for distribution and planning were key, and West Virginia mobilized many of the key players during the early months of the pandemic for COVID-19 response and community testing. Frontline healthcare workers, members of the West Virginia National Guard, employees of the Department of Health and Human Resources, employees of the Centers for Disease Control, representatives from the Board of Pharmacy, local pharmacies, and many others began to work together under what was later termed the Joint Inter-Agency Task Force (JIATF), and under the direction of Governor Justice, the groundwork was laid for future success. This started with the state initially choosing not to opt into the federal vaccination program, which focused around a couple of the large national chain pharmacies as partners and instead relying on the West Virginia National Guard, local healthcare facilities, and independent pharmacies to administer vaccinations. The other key difference was Governor Justice's adamant stance on immunizing those at the highest risk first. As a state with a weighted population of residents over the age of 65 , immunizations started with nursing and long-term care facility residents and frontline healthcare workers. While other states and the national partners were still planning, West Virginia was getting shots in arms, and opening up additional groups each week to continue increasing the number of vaccinated residents. This quickly propelled the tiny state of West Virginia to the forefront of the nation, but it also showcased the adaptability of the organizations involved and their ability to work together, including local pharmacies and providers. Additionally, it showed the bond between West Virginians and the state's ability to erase political lines for the benefit of its people.

Well into the third month of vaccine delivery, West Virginia chose to opt into the federal vaccination program in order to secure access to additional doses throughout the state and to add in new locations for residents to seek immunizations. The age brackets continued to decrease as vaccines became more readily available and more residents were immunized; the state is currently vaccinating all residents without restrictions. 
To date, there have been over 675,000 residents who have received at least one dose of vaccine and nearly 500,000 residents who are fully vaccinated.

Personally, I have been honored to be a part of the COVID-19 response from the beginning. There have been numerous articles and news clips highlighting my personal efforts to assure each and every dose has an arm, even if it means driving to a patient's home. However, I want to quickly note that the success in West Virginia has been a team effort from Governor Justice down, and without each member doing their part, the story might have had a different ending.

The challenge for the remainder of the spring and summer of 2021 will be continuing to build on this success and striving for vaccination numbers that will allow the state to reach herd immunity. This means that vaccinators need to be well-versed and able to confront vaccine hesitancy, as well as willing to continue to provide access to residents as the total numbers served by clinics begin to decline. I have complete faith that the West Virginia healthcare providers and our support are up to the task, and I look forward to continued success.

\section{AUTHOR AFFILIATIONS}

1. Director of Pharmacy Operations, Fruth Pharmacy, Point Pleasant, West Virginia 